\title{
Regional needs, regional targeting and regional growth: an assessment of EU Cohesion Policy in UK regions
}

\section{Marco Di Cataldo \& Vassilis Monastiriotis}

To cite this article: Marco Di Cataldo \& Vassilis Monastiriotis (2018): Regional needs, regional targeting and regional growth: an assessment of EU Cohesion Policy in UK regions, Regional Studies, DOI: 10.1080/00343404.2018.1498073

To link to this article: https://doi.org/10.1080/00343404.2018.1498073

+ View supplementary material

曲 Published online: 03 Aug 2018.

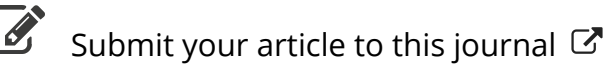

Џll Article views: 43

View Crossmark data $\nearrow$ 


\title{
Regional needs, regional targeting and regional growth: an assessment of EU Cohesion Policy in UK regions
}

\author{
Marco Di Cataldo ${ }^{\mathbf{a}} \odot$ and Vassilis Monastiriotis ${ }^{\mathbf{b}} \odot$
}

\begin{abstract}
With the prospective exit of the UK from the European Union (EU), a crucial question is whether EU Structural Funds have been beneficial for the country and which aspects of Cohesion Policy should be maintained if EU funds are to be replaced. This paper addresses this question through a twofold investigation, assessing not only whether but also how EU funds have contributed to regional growth in the UK from 1994 to 2013. It documents a significant and robust effect of Cohesion Policy in the UK, with higher proportions of Structural Funds associated with higher economic growth both on the whole and particularly in the less developed regions of the country. In addition, it is shown that the strategic orientation of investments also plays a distinct role for regional growth. While concentration of investments on specific pillars seems to have no direct growth effects, unless regions can rely on pre-existing competitive advantages in key development areas, clear evidence is unveiled that targeting investments to specific areas of relative regional need has a significant and autonomous effect on growth. These findings have important implications for the design of regional policy interventions in Britain after Brexit.

KEYWORDS

European Union Cohesion Policy; UK; Structural Funds; regional policy design; Brexit
\end{abstract}

JEL O18, R11, R53

HISTORY Received 24 May 2017; in revised form 26 June 2018

\section{INTRODUCTION}

One consequence of the UK's exit from the European Union (EU) will be that the country will no longer be eligible to receive EU Structural Funds. This represents not only a potential financial loss in the area of local economic development policies but also a prospective problem of policy design - indeed, it has been argued that filling the policy vacuum generated by the loss of Cohesion Policy after Brexit will be far from simple (Bachtler \& Begg, 2017). In this context, it appears timely to ask whether EU funds have contributed to fostering the economic performance of recipient UK regions and examine what have been the successful features of EU spending that should perhaps be maintained once regional policy responsibility becomes fully 'repatriated' to the national level.

The existing economic literature provides rather little evidence on these important issues. Despite the bourgeoning research on the economic effects and overall effectiveness of EU Cohesion Policy, studies examining the contribution of Structural Funds on regional economic performance in the UK are far and few between (a recent exception, in the impact-assessment tradition, is Di Cataldo, 2017). ${ }^{1}$ The evidence produced by the broader European literature is also of limited help, as findings on the economic effects of the policy are not fully conclusive (cf. Becker, Egger, \& von Ehrlich, 2010, 2012; BouayadAgha, Turpinn, \& Védrine, 2013; Cerqua \& Pellegrini, 2017; Dall'erba \& Le Gallo, 2008) and seem to vary across national and regional contexts (Bachtrögler, Fratesi, \& Perucca, 2018; Crescenzi \& Giua, 2018).

More importantly, the literature is also relatively moot on how the prioritizing on specific expenditure categories may influence the effectiveness of Cohesion Policy expenditures. Only a handful of studies exist on this issue, providing mostly indirect evidence on the role of prioritizing specific investment axes vis-à-vis balancing expenditures across different policy targets (Rodríguez-Pose \& Fratesi, 2004), or on the role of targeting interventions to the local specificities and factor endowments of regions (Crescenzi, Fratesi, \& Monastiriotis, 2017; Crescenzi \& Giua, 2016; Sotiriou \& Tsiapa, 2015). ${ }^{2}$

\section{CONTACT}

a (Corresponding author) m.di-cataldo@lse.ac.uk

Department of Geography and Environment, London School of Economics, London, UK.

b_v.monastiriotis@lse.ac.uk

London School of Economics, European Institute, London, UK.

(-) Supplemental data for this article can be accessed http://dx.doi.org/10.1080/00343404.2018.1498073. 
In this paper we focus exclusively on the UK context and build on the literature assessing the strategic designs of EU policies to assess empirically not only whether but also how EU funds have contributed to improve the economic performance of UK regions. Using recently released data with detailed information on Structural Funds payments by programming period and by category of expenditures, we produce a unique analysis of the regional economic effect of Cohesion Policy in the UK, examining the role that aspects of design and fund deployment have had on this.

We start by testing the economic returns of EU funds using annual data for 1994-2013. We find a significant and robust effect, showing that higher proportions of $\mathrm{EU}$ Structural Funds are associated with higher economic growth rates. This relationship appears strictly linear; even among the regions receiving the largest bulk of the funds we find no evidence of either threshold or exhaustion effects. Assignment into Objective 1 or Convergence status is positively and significantly associated with regional growth, a result which is mainly due to a positive effect of receiving such status ('entering' into the programme) rather than to being adversely affected by losing eligibility ('de-assignment').

Subsequently, we focus on the strategic orientation of investments, drawing on a consistent classification of expenditures along five development pillars, for the two programming periods $2000-06$ and 2007-13. We focus on two key aspects: (1) the concentration of funds across a range of interventions and in areas of pre-existing regional strength; and (2) the 'alignment' between committed expenditures and measured regional 'needs'. While we find little evidence that focusing on any one pillar has direct growth impacts - the concentration of funding seems to be on the whole harmful for growth, unless it concerns spending on an existing specialization in innovation or tourism - we uncover clear evidence that misalignment between effort (the allocation of funds to specific categories) and regional needs (the areas of main weakness vis-à-vis other regions) significantly penalizes the economic performance of a region. This suggests that investment allocation and fund-deployment strategies have real efficiency implications: carefully identifying and targeting the main socioeconomic disadvantages of regions can increase the effectiveness of the policy interventions for any amount of available resources.

The paper is organized as follows. The second section presents a background discussion on the rationale behind EU development strategies, reviewing the existing literature assessing the effectiveness of different strategic designs and explaining our own conceptualization of this. The third section discusses the data and estimation approach. The fourth section explains our approach to measuring regional needs and gives a descriptive picture of the distribution of relative regional need across the UK NUTS-2 regions (Nomenclature of Territorial Units for Statistics). The fifth section presents the first part of the empirical analysis, assessing the relationship between Cohesion Policy expenditure and economic growth. The sixth section examines instead the growth effects of fund-deployment characteristics (concentration, targeting). The seventh section discusses the implications of the findings and concludes.

\section{THE ISSUE OF POLICY DESIGN: LITERATURE, POLICY AND CONCEPTUAL FRAME}

The regional development policies promoted by the EU have evolved over time. In its origin, EU Cohesion Policy was conceived as a tool to counterbalance the regional disparities inevitably emerging from the market system (Armstrong, 2011). The main focus was on physical capital investment, particularly transport infrastructure, and the primary objective was economic convergence (European Commission, 2014). Following political as well as academic criticism of this approach, the focus gradually shifted from redistribution to allocation and from large infrastructure investment to softer infrastructures (research and development (R\&D), education) and a more diversified investment mix; while more recent reforms - stimulated further by a number of influential contributions (Barca, 2009; Barca, McCann, \& Rodríguez-Pose, 2012; Camagni \& Capello, 2015; Farole, Rodríguez-Pose, \& Storper, 2011) - shifted the strategic orientation of Cohesion Policy towards more comprehensive and integrated interventions (Bachtler, Martins, Wostner, \& Zuber, 2017).

According to the current vision, a differentiated ('place-based') approach in each regional context represents the key for the success of development strategies - infused with a 'smart specialization' perspective (McCann \& Ortega-Argilés, 2015), based on fostering the key innovative assets of each region and on identifying key areas of weakness and the combination of advantages that can stimulate growth.

In poorer regions, infrastructure provision is now mixed with important measures in other development areas such as education, business development and the promotion of innovation. Moreover, the new policy paradigm gives increasing importance to local and regional actors in the definition of development strategies. Mobilizing local players, it is claimed, allows a deeper understanding of the specific needs and competitive advantage of places to be gained and bottom-up interventions to be designed accordingly (Barca et al., 2012). Regional policies carefully considering local preferences and specificities are regarded as superior to top-down approaches in their capacity to stimulate, otherwise untapped, economic potential.

Following these changes, a small literature has started to emerge seeking to assess how the design of EU strategies conditions the effectiveness of Cohesion Policy. Building in part on the earlier work by Rodríguez-Pose and Fratesi (2004), who showed that wrongly targeted strategies overemphasizing single-development axes (e.g., transport infrastructure) are less growth conducive, two recent studies examined specifically the issue of concentration of funds and the relative productivity of investments across axes. Sotiriou and Tsiapa (2015) looked at the case of Greece, 
finding that growth is faster in regions where the investment mix is related to the local endowments, i.e., that investing in one's own area of specialization matters, at least for some spending categories.

Concerning the question of the economic returns of bottom-up policy designs, Crescenzi and Giua (2016) showed that the most effective strategies are those mixing top-down with bottom-up approaches. An alternative line of investigation has been opened recently by the work of Crescenzi et al. (2017). Using a selected sample of 15 regions from across the EU, the authors found that congruence between regional socioeconomic needs and spending priorities is a significant factor influencing the effectiveness of Cohesion Policy.

The present analysis follows this emerging literature and seeks to provide a comprehensive assessment of fund-deployment strategies. Its conceptual framework identifies two, not necessarily orthogonal, axes along which such strategies are designed. The first concerns the issue of concentration. Concentrating expenditures in a small number of thematic areas ${ }^{3}$ creates advantages of scale and resource mobilization and thus has the potential to maximize the returns to investment. Inversely, however, concentration may be less efficient if there are diminishing returns to investment; while it may also give rise to problems of information (how to choose the appropriate thematic areas of intervention), coordination (how to maximize the benefits from intervening in one area if synergies with other areas are not fully exploited due to underfunding) and risk diversification (what happens if the targeted area - say, tourism or industry - is negatively affected by a shock or if targeting in that policy area fails).

The second axis concerns the issue of targeting. Targeting investments in the areas of relative strength may be an effective tool for maximizing returns to investment and, ultimately, regional growth. However, in the presence of cross-thematic complementarities and/or in the absence of supply-side constraints within the targeted area, targeting may in fact be less effective for growth and less efficient economically. Take, for example, the case of a tourist area, such as Cornwall. Investing further in tourism and regeneration may have an obvious appeal, especially in relation to the information problem mentioned above. But it may be completely ineffective if further tourism development in the region is hindered not by supply-side constraints within the tourism sector (including the availability of land, of a workforce possessing relevant skills or of branding initiatives) but, say, by accessibility (requiring investment in transport infrastructure) or by a lack of supporting industries (e.g., legal and accounting services - requiring investments in business development and human resources). Theoretically, then, it is unclear whether concentration of funding (both thematic and geographical) and targeting on thematic areas of advantage or areas of regional need have positive growth effects. This becomes an empirical question, which we address in the remainder of this paper. The next section explains in detail how we operationalize empirically the conceptual frame presented.

\section{DATA AND EMPIRICAL APPROACH}

The analysis assesses three dimensions of EU funds, one related to the effect of total investments and two to the effectiveness of the design of $\mathrm{EU}$ investment programmes. The first dimension concerns the actual investment effort and its distribution across regions. For this, we use standard measures of assignment and intensity of treatment, as employed elsewhere in the literature. Assignment is captured by a dichotomous (dummy) variable taking the value of 1 for each region belonging to 'Objective 1' (for 1994-2006) or 'Convergence' status (for 2007-13). Intensity is measured as a continuous variable reflecting the proportion of EU funds paid to UK regions, specified alternatively in per capita terms or as a share of regional gross domestic product (GDP). For this analysis, we use data on total annual payments to the 37 UK NUTS-2 regions from 1994 to 2013 derived from the Structural Funds database of the European Commission (DG Regional Policy). ${ }^{4}$

The second dimension refers to the relative policy effort, i.e., the allocation of funds across investment pillars within regions. For this, we rely on a unique data set of commitment allocations, reported at the level of specific fields of interventions aggregated by programming period for 2000-06 and 2007-13. ${ }^{5}$ Based on this, we constructed aggregate measures of commitment allocations along five key investment pillars corresponding to: (1) Transport infrastructure; (2) Business support; (3) Research, technological development and innovation (RTDI); (4) Human resources; and (5) Tourism, culture and regeneration. ${ }^{6}$ The selection of these pillars was inspired by macro-aggregations of expenditure categories defined by the European Commission in the two analyzed periods, as well as by previous studies considering subdivisions of Structural Funds by category (Rodríguez-Pose \& Fratesi, 2004; Sotiriou \& Tsiapa, 2015). ${ }^{7}$ Following, we calculated the regional investment shares for each pillar (fund commitments in the pillar in the region divided by total fund commitments in the region) as well as a measure of concentration of effort (the sum of the squares of these shares based on a Herfindahl index), which we use in the empirical analysis.

The third dimension relates to how funds have been targeted towards investment axes with respect to regional advantages and needs. Following Crescenzi et al. (2017), our main hypothesis is that targeting of expenditures towards areas of regional need (alignment between effort and need) can be growth enhancing. As explained in the second section, a competing hypothesis is that growth is enhanced by the allocation of funds into areas of advantage (prioritizing on a region's strengths). To examine these two hypotheses, we have constructed a measure of specialization (spending on one's own area of advantage) and two measures of needs-effort misalignment (horizontal and vertical), as explained in the next section, which we treat as our policy variables. Following Sotiriou and Tsiapa (2015), we also implement a complementary test for the second hypothesis by estimating separate growth regressions per 
expenditure category and examining the interaction effect between per capita expenditures in the category of interest and a measure of relative performance of each region in this category.

For all three dimensions, the empirical analysis employs a specification of the following form:

$$
\begin{aligned}
\Delta \ln (Y / P)_{i, t}= & \beta_{1} \ln (Y)_{i, t-1}+\beta_{2} X_{i, t}+\beta_{3} \mathrm{EU}_{i, t} \\
& +\varphi_{i}+\tau_{t}+\varepsilon_{i, t}
\end{aligned}
$$

where $\Delta$ is the first-differencing operator, $i$ and $t$ index regions and time respectively; $Y$ is regional GDP; $P$ is population; $X_{i, t}$ is a set of regional characteristics including the regional unemployment rate, the share of tertiary education degree holders in the regional workforce, the share of agricultural employment and a measure of innovation capacity (patent applications per 1000 inhabitants); $\mathrm{EU}_{i, t}$ is our measure relating to EU funds; $\varphi_{i}$ and $\tau_{t}$ are vectors of region-specific and time dummies capturing permanent differences in growth rates across regions and national business-cycle effects respectively; and $\varepsilon_{i, t}$ is a vector of identically and independently distributed (iid) residuals.

When estimating equation (1) using the annual data set, $t$ indexes years, $t-1$ stands for values 1 year ago, and all $X_{i, t}$ and $\mathrm{EU}_{i, t}$ variables are defined contemporaneously and measured on an annual basis, while the dependent variable is the annual change in the log of per capita GDP. Instead, when using the period-specific data set, $t$ indexes programming periods; $t-1$ stands for the year before the start of the programming period $t, X_{i, t}$ and $\mathrm{EU}_{i, t}$ are programming period averages; and the dependent variable is measured as the average annualized regional growth rate of GDP per capita. In all cases, standard errors are clustered at the NUTS-2 level, the one at which Cohesion Policy eligibility is assigned, and all models are estimated with time and region fixed effects.

Although this research design does not offer an identification strategy, we note that our policy variables (funding commitments, misalignment measures etc.) are strictly predetermined and thus exogenous in a Granger sense. Concerns about selection (e.g., that more expenditures go to regions with high future growth potential) are further minimized by the inclusion of regional fixed effects and of the initial level of per capita GDP; ${ }^{8}$ while concerns about confoundedness are also limited given the lack of complementarity between EU Cohesion Policy and domestic regionally identifiable capital expenditures (see below). We thus think of our estimates not only as general equilibrium effects but also as indicative of the direct effect of the policy variables - and thus also of the 'counterfactual' of the absence of the policy treatment.

EU Cohesion Funds represent only a small portion of total regional investments in the UK. For example, in the period 2000/01-2005/06, domestic regionally identifiable capital expenditures averaged $£ 28.22$ billion per annum. This contrasts with the $€ 2.46$ billion (approximately $£ 1.72$ billion) of total annual funding (commitments) derived from EU Cohesion Policy during the 2000-06 programming period. In those terms, EU Cohesion Policy represents only a small fraction of UK regional investments. It should be noted, however, that Cohesion Policy expenditures are much more concentrated, geographically and thematically, and targeted on more specific development activities. For example, in Wales, total EU expenditure represented in the same period over $22 \%$ of total public investment; while across the $\mathrm{UK}$, in the category of business and enterprise development, EU Cohesion Funds represented around one-third of total regional investment. Importantly, London and the South East attract around $30 \%$ of regionally identifiable UK capital expenditure, but only $6 \%$ of EU funds allocated to the UK; while at the NUTS-1 level, at which comparable data are available, the regional allocation of EU funds seems completely uncorrelated to that of domestic UK capital expenditures. ${ }^{9}$ Thus, although a small proportion of total regional effort, EU Cohesion Policy appears to be largely independent of UK regional policy (at least in terms of the spatial allocation of domestic capital expenditures), consistent with the principle of additionality. For this reason, the focus in this paper is exclusively on the regional growth effects of EU funds.

\section{THE MEASUREMENT OF REGIONAL ADVANTAGE AND NEED}

As noted, our analysis of the issue of targeting relies on measures of relative regional advantage and need. To measure these, we move beyond aggregate measures of performance, such as GDP per capita, and look instead at detailed socioeconomic variables that map onto the five investment pillars to which our expenditure data relate. We started by selecting a number of socioeconomic variables that measure the relative performance of regions along aspects that map directly onto the five investment pillars listed above. Each proxy variable was chosen by relying on the existing literature approximating context conditions of the same or similar nature. These were: the stock of roads per inhabitant and per $\mathrm{km}^{2}$ of land (for the Transport infrastructure pillar) (Crescenzi \& Rodríguez-Pose, 2012; Del Bo \& Florio, 2012); the share of employed people in high-tech sectors and the number of patent applications per 1000 inhabitants (for RTDI) (Acs, Anselin, \& Varga, 2002; Griliches, 1990); the share of tertiary degree holders in employment and the (inverse of the) percentage of unemployment benefit claimants (for the Human resources pillar) (Nehru, Swanson, \& Dubey, 1993); a measure of competitiveness (the inverse of regional unit labour costs in manufacturing) and the rate of investment per employee in manufacturing (for the Business support pillar) (Fagerberg, 1988); and the numbers of tourist arrivals per inhabitant and of tourist establishments per 1000 inhabitants (for the Tourism, culture and regeneration pillar) (Sinclair, 1998). ${ }^{10}$ For each of these, we collected data for the four years to the start of each programming period and calculated averages across the four years, so as to capture the conditions characterizing the regions in the period when the relevant funding commitments were being designated. We standardized these variables using the linear 
scale transformation method and aggregated them into five pillars. The resulting variables represent a vertical (withinpillar across-regions) measure of relative regional strength; and the inverse of these ranks represents instead a measure of relative regional need per pillar. A note of caution should be added here. Although, as mentioned, our definition of needs is validated by the use in the literature of the selected indicators, the results are, of course, conditional on the assumption that these indicators capture successfully the relevant local needs in each policy pillar. In parts of the analysis we test the sensitivity of the results to this by employing alternative measures for the definition of need (e.g., for the Business support pillar ${ }^{11}$ ).

To measure advantage, we drew on the first type of rankings (relative strength) and assigned the pillar of strongest relative performance (lowest rank) of each region as this region's area of advantage. By interacting this assignment indicator with our pillar-specific per capita investments, we derived a new variable (specialization) measuring, for each region, the per capita expenditure on the investment pillar on which this region has a relative advantage compared with other regions. We use this measure to examine whether targeting expenditures on a region's own area of strength enhances regional growth. ${ }^{12}$

To measure need, we developed two complementary measures. The first is a vertical measure of overall regional need, which we obtain by taking the inverse rank of the vertical performance scores mentioned above and averaging them across the five pillars, for each region. ${ }^{13}$ The second is a horizontal measure of need, showing the intensity of relative need of each region in each investment pillar, which we derived by taking the same inverse rank-scores and ranking each pillar according to its score within each region. ${ }^{14}$ Subsequently, we implemented a similar analysis for the per capita expenditures, deriving a vertical (how regions rank nationally in terms of the per capita funding they receive) and a horizontal rank-score (how pillars rank, within each region, in terms of their funding allocations relative to their allocations nationally).

Based on these rank-scores, we proceeded to construct our two indicators of horizontal and vertical misalignment. Vertical misalignment is measured as the absolute difference between the vertical rank-score of funding commitments and the vertical rank-score of regional need. It thus captures how dissimilar is a region's national ranking in terms of funds committed per capita to its national (vertical) ranking in terms of relative need. In turn, horizontal misalignment is measured as the absolute difference between the horizontal (within-regions) rank-score of commitments and the horizontal rank-score of regional need (across pillars within regions). This captures how dissimilar is the allocation of committed funds across pillars within each region to the same region's relative ranking of need, nationally, in each of the five pillars. For both measures, a value of zero shows perfect alignment between regional needs and the prioritization of policy interventions; while higher values show diminishing congruence between effort and need.
Figure 1 presents a descriptive picture of our measures of need, linked to the allocation of Cohesion Policy funds across investment pillars. Figure 1(a) depicts the geographical distribution of our vertical measure of overall regional need (circles layer) against that of the overall funds committed to each of the regions (shaded layer) using, for ease of presentation, averages across the two programming periods of our data. Each of the other maps shows, for one of the five pillars, the position of the UK NUTS-2 regions with regard to their allocation of EU funds in this pillar (measured as a share to total) and with regard to their ranking in terms of need in the same category (horizontal measures of need). ${ }^{15}$

As can be seen, there are sometimes sizeable differences in the two geographies of effort and of need; while the extent of alignment between effort and needs varies substantially across categories. Only one of the five areas receiving the highest per capita commitments of EU funds is also classified as a 'high need' region (South Yorkshire) according to our measures; ${ }^{16}$ while the majority of regions classified as 'high need' rank in the medium-high category in terms of funds committed. Still, some degree of congruence is also present: the majority of regions located in the broader South East, which have low per capita commitments, appear also as regions of low relative need. Among the pillar-specific measures, misalignment appears to be particularly high in the cases of Human resources (where low-need regions in the South receive more funds, in part because of EU fund allocation rules) and Transport infrastructure (where our measure of road density in per capita terms weighs heavily in favour of urban and metropolitan areas); and lowest in the case of RTDI (where a significant amount is allocated to the high-need Objective 1 regions and the old industrial heartlands).

\section{EUROPEAN UNION FUNDS AND ECONOMIC GROWTH IN UK REGIONS}

We start the empirical analysis by examining the overall impact of EU Structural Funds on economic growth across the UK regions, i.e., the issues of effort and assignment as mentioned previously. The results of this analysis are illustrated in Table 1.

Table 1, column (1), presents a parsimonious specification of our model, including region and year dummies, but no further control variables. In this initial specification, we find clear evidence of a positive relationship between EU grants and regional growth. The estimated coefficient is significant at $1 \%$ and shows a rather sizeable effect - with a doubling of per capita funds (e.g., from our sample average of $€ 27.70$ to $€ 55.40)$ associated with a growth rate higher by 0.23 percentage points (or by $8.8 \%$ based on average growth rates for the period 1994-2013). Expressed in different terms, this shows that an additional $€ 1$ of $\mathrm{EU}$ funds per capita (a cost of about $€ 65$ million) would raise average per capita incomes by $€ 1.87$ (a gain of approximately $£ 121$ million). The effect loses somewhat its statistical significance when controls are included in the model (column (2)), but it increases in magnitude, corresponding 


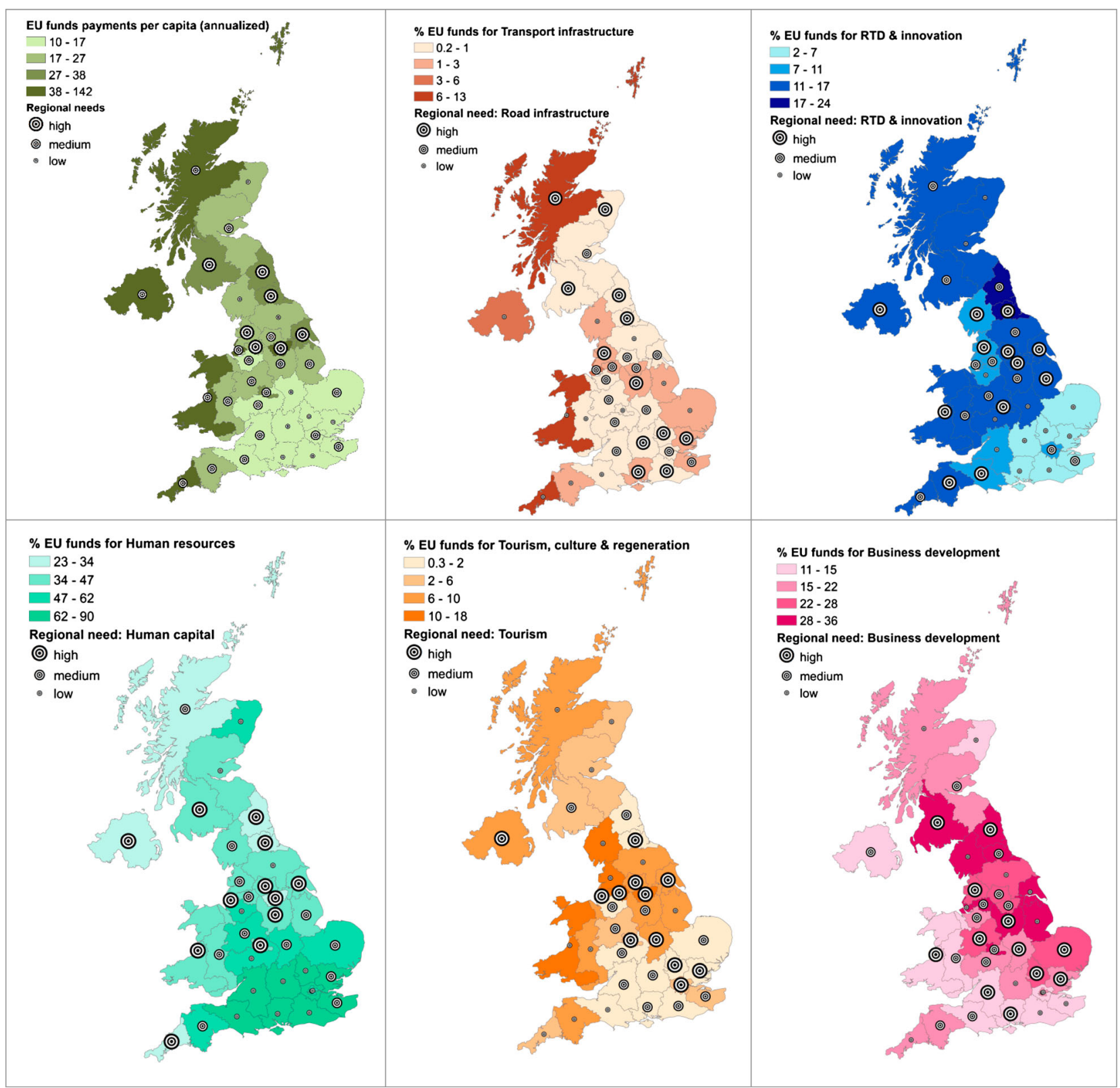

Figure 1. European Union (EU) funds spent by category and needs of NUTS-2 regions, 2000-06 and 2007-13.

Note: Measures of relative regional need (circles) and shares of EU fund commitments (shaded areas) are as described in the text. Darker shades correspond to higher shares of EU funds. Larger circles correspond to higher values of relative need (categorized by tercile as high, medium and low).

now to a rise of average growth rates by 0.32 percentage points for a doubling of EU funds. ${ }^{17}$ A similarly large, positive and statistically significant effect is also obtained in column (3), where we examine the effect of assignment into Objective 1 status. The results show that regions obtaining Objective 1 funds grew on average by 0.8 percentage points faster than other regions, annually, during the 1994-2013 period. The inclusion of the Objective 1 dummy changes little the obtained beta-convergence coefficient (from 0.307 to 0.297 ) and thus the estimated effect of assignment cannot be seen as capturing an inverse income-selection effect, whereby poorer regions become assigned to Objective 1 status and at the same time grow faster due to neoclassical convergence.
Table 1, column (4), tests for a non-linear effect of EU funds on economic growth. Previous studies have evidenced the presence of decreasing returns to Cohesion Policy expenditures in European regions (Becker, Egger, \& von Ehrlich, 2012; Cerqua \& Pellegrini, 2017). In our estimation (column (4)), the quadratic term of EU funds is negative - consistent with the hypothesis of decreasing returns - but not statistically significant. This indicates that in the UK case, the level of EU expenditures has not been sufficiently high for decreasing returns to kick in. Indeed, no region in our sample surpasses the 'maximum desirable intensity' threshold estimated by Cerqua and Pellegrini (2017) using EU-28 data. In line with this, the positive and significant coefficient of the interaction term 
Table 1. European Union (EU) funds and economic growth in UK NUTS-2 regions, 1994-2013.

\begin{tabular}{|c|c|c|c|c|c|c|c|c|}
\hline \multirow[b]{2}{*}{ Dependent variable: $\Delta$ ln GDP per capita } & \multicolumn{5}{|c|}{ Annual data } & \multicolumn{3}{|c|}{ Programming periods } \\
\hline & (1) & (2) & (3) & (4) & (5) & (6) & (7) & (8) \\
\hline lagged In GDP per capita & $\begin{array}{c}-0.220 * * * \\
(0.0390)\end{array}$ & $\begin{array}{c}-0.307^{* * *} \\
(0.0350)\end{array}$ & $\begin{array}{c}-0.297^{* * *} \\
(0.0340)\end{array}$ & $\begin{array}{c}-0.307^{* * *} \\
(0.0351)\end{array}$ & $\begin{array}{c}-0.303^{* * *} \\
(0.0364)\end{array}$ & $\begin{array}{c}-0.190 * * * \\
(0.0243)\end{array}$ & $\begin{array}{c}-0.182^{* * *} \\
(0.0246)\end{array}$ & $\begin{array}{c}-0.183^{* * *} \\
(0.0146)\end{array}$ \\
\hline EU funds per capita & $\begin{array}{c}0.000084^{* * *} \\
(2.95 \mathrm{e}-05)\end{array}$ & $\begin{array}{c}0.000114^{* *} \\
(4.49 e-05)\end{array}$ & & $\begin{array}{l}0.000135^{*} \\
(7.67 \mathrm{e}-05)\end{array}$ & $\begin{array}{l}0.000132 * \\
(6.96 e-05)\end{array}$ & $\begin{array}{l}0.000083^{*} \\
(4.21 \mathrm{e}-05)\end{array}$ & & \\
\hline EU funds per capita squared & & & & $\begin{array}{l}-1.05 e-07 \\
(3.89 e-07)\end{array}$ & & & & \\
\hline Objective 1 regions & & & $\begin{array}{l}0.00857^{*} \\
(0.00437)\end{array}$ & & $\begin{array}{l}0.00885^{*} \\
(0.00516)\end{array}$ & & $\begin{array}{c}0.00755^{* * *} \\
(0.00247)\end{array}$ & \\
\hline (Obj1 regions) $\times$ (EU funds per capita) & & & & & $\begin{array}{c}0.000082 * * \\
(3.27 e-05)\end{array}$ & & & \\
\hline Obj1 status: entering & & & & & & & & $\begin{array}{l}0.0108 * * \\
(0.00480)\end{array}$ \\
\hline Obj1 status: exiting & & & & & & & & $\begin{array}{c}0.00389 \\
(0.00582)\end{array}$ \\
\hline Controls & & $\checkmark$ & $\checkmark$ & $\checkmark$ & $\checkmark$ & $\checkmark$ & $\checkmark$ & $\checkmark$ \\
\hline Region dummies & $\checkmark$ & $\checkmark$ & $\checkmark$ & $\checkmark$ & $\checkmark$ & $\checkmark$ & $\checkmark$ & $\checkmark$ \\
\hline Year/programming period dummies & $\checkmark$ & $\checkmark$ & $\checkmark$ & $\checkmark$ & $\checkmark$ & $\checkmark$ & $\checkmark$ & $\checkmark$ \\
\hline Observations & 693 & 613 & 613 & 613 & 613 & 109 & 109 & 109 \\
\hline$R^{2}$ & 0.751 & 0.778 & 0.776 & 0.778 & 0.778 & 0.953 & 0.953 & 0.953 \\
\hline NUTS-2 regions & 37 & 37 & 37 & 37 & 37 & 37 & 37 & 37 \\
\hline VIF statistic (overall) & 1.03 & 1.62 & 1.60 & 3.06 & 2.17 & 1.99 & 1.95 & 1.80 \\
\hline \multicolumn{9}{|c|}{$\begin{array}{l}\text { Notes: Clustered standard errors at the NUTS-2 level are shown in parentheses. Year dummies are included in columns (1)-(5); programming period dummies are included in columns (6)-(8). EU funds per capita: payments per } \\
\text { year (columns 1, 2, 4,5); and payments per programming period (column 6). VIF, variance inflation factor. Results of columns (2) and (3) displaying the coefficients of control variables are reported in Table A8 in Appendix A in the } \\
\text { supplemental data online. } \\
* * * p<0.01 ;{ }^{* *} p<0.05 ;{ }^{*} p<0.1 \text {. }\end{array}$} \\
\hline
\end{tabular}


between the Objective 1 dummy and EU funds in column (5) shows that, even among the highly funded Objective 1 regions, those receiving more funds are those displaying the fastest growth rates.

The next step is to examine whether the results obtained from the annual data replicate themselves across programming periods. To do so, we aggregate the annual data to the level of the three programming periods and re-estimate the models of columns (2) and (3) (see columns (6) and (7)). As can be seen, the results remain particularly stable, providing additional confidence on the growth effects estimated from the annual data and suggesting that these effects are not driven merely by year-on-year variations, which are more likely to suffer from endogeneity problems. As a further test of robustness, the last column of Table 1 examines whether the positive estimate found for assignment to Objective 1 status may be driven instead by a negative effect of 'de-assignment' (losing Objective 1 eligibility ${ }^{18}$ ). We do this by introducing separate dummies for regions entering and exiting Objective 1 status. The results show that the relationship obtained earlier is not driven by 'de-assignment' but exclusively by entry into Objective 1 status. This intuitive result increases further our confidence in the validity of the results and of our interpretation of them as showing evidence of a robust relationship between Cohesion Policy interventions and regional growth performance.

\section{THE IMPACT OF CONCENTRATION AND TARGETING}

The results of the previous section present evidence for the positive role played by Cohesion Policy in the UK. This section takes the analysis further to examine the role played by aspects of design, as discussed previously. We first look at the effect of concentrating Cohesion Policy interventions on specific investment pillars; and then move on to study the role of the alignment of investments with observed socioeconomic needs of regions or alternatively with regional areas of specialization. ${ }^{19}$

\section{Concentration}

Our examination of the issue of concentration is threefold. First, testing whether the positive effect found for Cohesion Policy interventions at large is specific to any particular expenditure category. Second, testing whether a disproportionate allocation of funds to any one category has tractable beneficial effects on regional growth. Third, testing whether the overall concentration of funding produces in itself positive effects on regional growth. We present the results from these tests in Table 2 .

For completeness, we start in Table 2, column (1), by examining whether the positive effect of EU funds found earlier (column (6) in Table 1) is also present in our commitments data. As can be seen, the coefficient on total per capita commitments is positive and statistically significant (albeit smaller than in the case of actual payments over the three programming periods). This positive effect does not appear to be driven by any one particular spending category. In Table 2, column (2), where we introduce the per capita commitments separately for each pillar, no single category emerges as the most growth conducive, as none passes the standard thresholds of statistical significance. Interestingly, on the whole, the pillar variables are jointly statistically significant, as reported in the $F$-test in Table 2. Even though in statistical terms this indicates the presence of multicollinearity, in analytical terms it suggests that concentration of funds in specific categories does not contribute positively to regional growth, even if jointly funding is beneficial.

Similar evidence is obtained when we look instead at the sectoral shares over total commitments per region, as shown in Table 2, column (3). The shares for Business development and Transport infrastructure return coefficients that are positive and marginally significant; jointly all shares are again statistically significant, but overall the results do not provide strong evidence of a positive effect of concentration of committed expenditures on growth. Indeed, the evidence suggests that, if anything, concentration may be harmful to regional growth: in column (4) the Herfindahl measure of concentration returns a negative and statistically significant coefficient.

All the results seem to indicate that, in the UK case, the thematic concentration of EU funds has no beneficial effect on growth. Instead, it appears that it is the combination of commitments across investment axes that creates positive synergies.

\section{Targeting}

We now turn to the examination of the growth effects of the three variables related to targeting. The core results from our analysis of this are reported in Table $3 .^{20}$ As can be seen, we find strong evidence that lack of congruence between relative regional needs and the withinregions allocation of the available funds (horizontal misalignment) is negatively associated with regional growth. The obtained coefficient in column (1) is statistically significant and quite sizeable in magnitude, suggesting that a two-unit rise in horizontal misalignment (equal to $10 \%$ of the theoretical maximum) is associated with a decline in regional growth by 0.19 percentage points. This represents without doubt a rather significant economic cost.

In contrast, our evidence suggests that vertical misalignment and our alternative measure of spending on one's area of specialization have no impact on regional growth. Vertical misalignment returns a highly insignificant effect, both when using our preferred sector-based definition (column (2)) and when using the alternative definition of need based on the ranking of regions in terms of their GDP per capita (column (3)). Likewise, the variable measuring expenditures in a region's area of specialization (column (4)) also returns a non-statistically significant effect, indicating that, on the whole, targeting investments on a region's area of advantage does not enhance regional growth.

All these results remain unchanged when we estimate a full model that includes all three variables linked to targeting of investments (column (5)). Vertical misalignment and 
Table 2. Sectoral concentration of European Union (EU) funds by programming period and economic growth in UK NUTS-2 regions, 2000-13.

\begin{tabular}{lcccc}
\hline Dependent variable: $\Delta$ In GDP per capita & \multicolumn{3}{c}{ Funds per capita } & Shares of total \\
\hline Initial In GDP per capita & $-0.124^{* * *}$ & $-0.102 * * *$ & $-0.130^{* * *}$ & $-0.130^{* * *}$ \\
& $(0.0350)$ & $(0.0258)$ & $(0.0271)$ & $(0.0238)$ \\
EU funds per capita & $2.36 \mathrm{e}-05^{*}$ & & & $\mathbf{( 3 )}$ \\
& $(1.35 \mathrm{e}-05)$ & &
\end{tabular}

EU funds for:

Human resources

$\begin{array}{cc}-9.94 \mathrm{e}-05 & -0.0136 \\ (0.000507) & (0.0293) \\ 0.000738 & 0.100 * \\ (0.000860) & (0.0580) \\ -9.06 \mathrm{e}-05 & 0.0277 \\ (5.83 \mathrm{e}-05) & (0.0401) \\ 0.000140 & -0.0279 \\ (0.000258) & (0.0275) \\ 0.000487 & 0.0292 * \\ (0.000292) & (0.0151)\end{array}$

Transport infrastructure

Research, technological development and innovation (RTDI)

Tourism, culture and regeneration

Business development

Concentration of funds

$\begin{array}{cccc} & & & -0.0224^{* *} \\ & & & (0.0104) \\ -0.0163^{* *} & -0.0117^{*} & -0.0158 & -0.0193^{* * *} \\ (0.00693) & (0.00620) & (0.0103) & (0.00678)\end{array}$

Controls

Region dummies

LM lag

0.1231
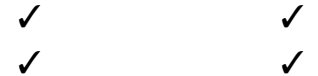

0.0025

0.1565

0.1022

LM error

(0.726)

$(0.960)$

(0.692)

(0.749)

0.6194

0.0087

0.3866

0.5528

(0.431)

(0.926)

(0.534)

(0.457)

VIF statistic (overall)

1.83

3.65

3.64

2.18

Observations

$R^{2}$

NUTS-2 regions

37

Joint significance of EU funds variables: F-test ( $p$-value)

$\begin{array}{cc}4.579 & 2.570 \\ (0.00247) & (0.0435)\end{array}$

Notes: Clustered standard errors at the NUTS-2 level are shown in parentheses. EU funds per capita: commitments per programming period. LM, Lagrange multiplier; VIF, variance inflation factor. Results of column (4) displaying the coefficients of control variables are reported in Table A8 in Appendix A in the supplemental data online.

${ }^{* * *} p<0.01 ;{ }^{* *} p<0.05 ;{ }^{*} p<0.1$.

targeting on specializations remain fully insignificant statistically, while horizontal misalignment continues to have a negative and statistically significant effect on growth.

The conclusion about the effect of spending on one's area of specialization is also supported by our further exploration of the issue, examining the interaction effect between spending and advantage as discussed above (the results are reported in Table A7 in Appendix A in the supplemental data online). In this case, two pillars - RTDI and Tourism, culture and regeneration - return a positive effect when interacted with a region's performance in the same area. In both cases, however, the direct effect of spending is negative, with the implication that the estimated interaction effect shows a relative, rather than an absolute, influence on regional growth (i.e., that spending on, say, tourism is more beneficial for touristic areas vis-à-vis others, but not necessarily beneficial in absolute terms). Spending on areas of advantage does not seem to produce any growth effects, absolute or relative, for investments in Transport infrastructure and Business development; while the effect is even negative for the case of Human resources (indicating that spending more on education in a region 
Table 3. Misalignment between regional targets and regional needs and economic growth in UK NUTS-2 regions, $2000-13$.

\begin{tabular}{|c|c|c|c|c|c|}
\hline Dependent variable: $\Delta$ In GDP per capita & $(1)$ & $(2)$ & (3) & (4) & (5) \\
\hline Initial In GDP per capita & $\begin{array}{c}-0.128^{* * *} \\
(0.0285)\end{array}$ & $\begin{array}{c}-0.123^{* * *} \\
(0.0312)\end{array}$ & $\begin{array}{c}-0.123^{* * *} \\
(0.0308)\end{array}$ & $\begin{array}{c}-0.123^{* * *} \\
(0.0310)\end{array}$ & $\begin{array}{c}-0.127^{* * *} \\
(0.0291)\end{array}$ \\
\hline Horizontal misalignment & $\begin{array}{c}-0.000945^{* *} \\
(0.000437)\end{array}$ & & & & $\begin{array}{c}-0.000915^{* *} \\
(0.000451)\end{array}$ \\
\hline Vertical misalignment (needs based) & & $\begin{array}{c}0.000106 \\
(0.000347)\end{array}$ & & & $\begin{array}{c}0.000152 \\
(0.000341)\end{array}$ \\
\hline Vertical misalignment (GDPpc based) & & & $\begin{array}{c}1.78 \mathrm{e}-05 \\
(0.000252)\end{array}$ & & \\
\hline Spending in area of specialization & & & & $\begin{array}{l}-0.00194 \\
(0.00688)\end{array}$ & $\begin{array}{l}-0.000016 \\
(0.000028)\end{array}$ \\
\hline Objective 1 regions & $\begin{array}{l}0.0131 * * \\
(0.00610)\end{array}$ & $\begin{array}{l}0.0128 * * \\
(0.00507)\end{array}$ & $\begin{array}{l}0.0128 * * \\
(0.00516)\end{array}$ & $\begin{array}{l}0.0138 * * \\
(0.00522)\end{array}$ & $\begin{array}{l}0.0147 * * \\
(0.00626)\end{array}$ \\
\hline Programming period 2007-2013 & $\begin{array}{l}-0.0136^{*} \\
(0.00675)\end{array}$ & $\begin{array}{l}-0.0133^{*} \\
(0.00717)\end{array}$ & $\begin{array}{l}-0.0131 * \\
(0.00702)\end{array}$ & $\begin{array}{l}-0.0132 * \\
(0.00694)\end{array}$ & $\begin{array}{c}-0.0145^{* *} \\
(0.00695)\end{array}$ \\
\hline Controls & $\checkmark$ & $\checkmark$ & $\checkmark$ & $\checkmark$ & $\checkmark$ \\
\hline Region dummies & $\checkmark$ & $\checkmark$ & $\checkmark$ & $\checkmark$ & $\checkmark$ \\
\hline LM lag & $\begin{array}{l}0.3775 \\
(0.539)\end{array}$ & $\begin{array}{l}0.3202 \\
(0.572)\end{array}$ & $\begin{array}{l}0.3212 \\
(0.571)\end{array}$ & $\begin{array}{l}0.2510 \\
(0.616)\end{array}$ & $\begin{array}{l}0.2622 \\
(0.609)\end{array}$ \\
\hline LM error & $\begin{array}{l}1.0925 \\
(0.296)\end{array}$ & $\begin{array}{l}0.7320 \\
(0.392)\end{array}$ & $\begin{array}{l}1.1500 \\
(0.284)\end{array}$ & $\begin{array}{l}0.6222 \\
(0.430)\end{array}$ & $\begin{array}{l}0.5439 \\
(0.461)\end{array}$ \\
\hline VIF statistic (overall) & 1.88 & 2.12 & 1.93 & 2.03 & 2.18 \\
\hline Observations & 74 & 74 & 74 & 74 & 74 \\
\hline$R^{2}$ & 0.979 & 0.976 & 0.976 & 0.976 & 0.979 \\
\hline NUTS-2 regions & 37 & 37 & 37 & 37 & 37 \\
\hline
\end{tabular}

Notes: Clustered standard errors at the NUTS-2 level are shown in parentheses. LM, Lagrange multiplier; VIF, variance inflation factor. Results of column (5) displaying the coefficients of control variables are reported in Table A8 in Appendix A in the supplemental data online.

${ }^{* * *} p<0.01 ;{ }^{* *} p<0.05 ;{ }^{*} p<0.1$.

that already possesses an educational advantage is not growth enhancing). These results are consistent with the evidence presented in Tables 2 and 3. Spending in individual investment categories seems to produce limited and on the whole non-traceable growth effects; while investing on one's area of advantage does not have a universally beneficial effect - even though it confers a relative advantage to regions specializing in $\mathrm{R} \& \mathrm{D}$ and tourism.

Invariably in all the models examined, the only effect that comes out consistently as the main influence on growth (besides assignment/intensity addressed in the fifth section) is that of horizontal misalignment. We see this as evidence showing not only that fund-deployment strategies at large matter for regional growth but also especially that targeting investments on a region's relative needs is an important ingredient for an effective regional development strategy - independently from the actual effort (scale of investments) allocated to that region.

\section{CONCLUSIONS AND POLICY IMPLICATIONS}

The recent decision of Britain to exit the EU has brought increased attention to the question of the effects of
Cohesion Policy interventions in the country and to the future of regional policy after Brexit. Despite a sizeable literature examining the growth effects of Cohesion Policy, evidence of its effects in the particular case of the UK is scarce. Also limited is the evidence on the role that the prioritizing of interventions into specific investment categories plays for the overall effectiveness of the policy and for regional growth at large.

In this paper we sought to address these questions using previously unused data for the UK covering three programming periods with detail on funding allocations across different investment categories. Inspired by some - rather selective - evidence on the issue of targeting offered recently by Crescenzi et al. (2017), we developed a novel methodology that allowed us to measure the alignment between regional needs and the prioritizing of commitments across investment pillars; and to examine, on the basis of this, how the level, concentration and targeting of investments impacts on regional growth.

Our results provide a unique picture with regard to the role of EU funds for regional growth in the UK. We have shown that the level of funds allocated to regions has a positive and non-exhaustible effect on growth, suggesting that Cohesion Policy interventions are productive 
irrespective of their scale. Further, we have shown that assignment into Objective 1 status also has a positive growth effect, which is additional to that of actual expenditures (Table 1, column (5)) and non-symmetric (column (8)). Concentration of spending, however, in any one investment pillar does not appear to bear an advantage. Although spending in transport and business development seems to be marginally more beneficial, by and large it is the total commitments that account for the positive effect of Cohesion Policy on growth. Indeed, over-concentration of commitments across categories seems, if anything, to be negatively associated with regional growth. This applies also to the case of concentration on specific areas of advantage. Our investigation of this showed that expenditures targeting areas of regional advantage do not produce positive growth effects on the whole: such targeting was found to have a positive effect only vis-à-vis other regions and only for regions specializing in innovation or tourism.

The key finding in our analysis concerns the impact of misalignment between the targeting of investment efforts and relative regional needs. On the one hand, the finding that vertical misalignment does not exert an influence on regional growth suggests that allocation of funds to regions is beneficial irrespective of whether these are the most needy in terms of socioeconomic indicators and, indeed, in terms of initial level of GDP per capita. This is on the whole a favourable outcome for Cohesion Policy: it suggests that Cohesion Policy interventions are highly productive irrespective of place and local conditions and, thus, that principles of allocation favouring poorer regions have no efficiency costs. On the other hand, the finding that horizontal misalignment between regional needs and investment allocations has a strong negative effect on regional growth speaks directly to the importance of giving due consideration to the local socioeconomic context - and needs - in the design and prioritizing of Cohesion Policy interventions. It is interesting to note that this is broadly the direction followed by Cohesion Policy in recent years - with more emphasis on 'place-based', tailored interventions that are more sensitive to local specificities and consider more carefully local socioeconomic assets and needs. Our results seem to vindicate and reinforce this approach. ${ }^{21}$

Our results also have strong implications in relation to Brexit. Cohesion Policy has been over a long period a significant stimulant to regional and national growth and, due to its focus on economically backward regions, a significant force for regional convergence in the country. The prospective withdrawal of the UK from the EU and the loss of eligibility for Cohesion Policy funding will thus not only deprive the UK's regional economies of an important source of investment funds but also most definitely of a mechanism via which forces of economic divergence have been in the past - at least partly - neutralized. It follows that policy efforts in the post-EU era, such as the 'Shared Prosperity Fund' proposed by the UK government as a replacement of EU funds, should concentrate on developing a similarly funded regional development policy which will substitute for the withdrawal of the Cohesion Policy interventions and, indeed, improve on these. On the basis of our results, positive features to maintain include the EU's approach to multi-annual programming and area designation (e.g., Objective 1 - as our results show an additional growth advantage from this). Inversely, features to improve upon would include perhaps an upping of the level of spending (as, at the level of EU expenditures in the country, we do not find any evidence of diminishing returns to investments), a move away from the concentration of funds in specific investment categories unless the regional structure is already predisposed for a good use of such investments, and, above all, increased attention to the targeting of investments so that they match the specific pre-existing weaknesses of each region.

\section{ACKNOWLEDGEMENTS}

The authors are thankful to the editor in charge and to two anonymous referees for their useful comments. Earlier versions of this paper were presented at the 57th Annual Congress of the European Regional Science Association (Groningen, the Netherlands), the 5th Master Class on Cohesion Policy (Brussels, Belgium), the Regional Studies Association Winter Conference (London, UK), and the 46th Annual Conference of the Regional Science Association International (RSAI) - British \& Irish Section (Harrogate, UK). The authors are thankful to the participants at these conferences for helpful comments and suggestions. They are also grateful for comments received from Peter Berkowitz, Andres Rodríguez-Pose, Riccardo Crescenzi and Lewis Dijkstra; as well as to Lewis Dijkstra, Domenico Gullo and Hugo Poelman for facilitating access to some of the data used here. All errors, omissions and points of interpretation remain with the authors.

\section{DISCLOSURE STATEMENT}

No potential conflict of interest was reported by the authors.

\section{NOTES}

1. Less recent studies often had either a narrower programme-specific focus (Armstrong \& Wells, 2006) or focused on issues of governance and institutional fit (Gripaios \& Bishop, 2006).

2. Policy design issues are more commonly addressed in the qualitative literature (Piattoni \& Polverari, 2016), but at the expense of statistical inference and generalization.

3. The discussion here focuses on the thematic dimension of fund deployment, i.e., the allocation of funds across investment axes. However, the frame used applies similarly to the geographical dimension. In this case, the questions of concern are whether funds should be targeting particular regions at all (concentration) and, if so, whether they should concentrate on the more advanced (higher-capacity) or more needy (potentially higher-returns) regions (targeting). 4. Payments from the 2007-13 programming period extend to 2014 and 2015 under the so-called $n+2$ rule. 
As these potentially overlap with payments from the 201420 programming period, which are not recorded in the data, these two years are excluded from the analysis.

5. These data were provided with permission by the DG Regional Policy. The authors are grateful to Lewis Dijkstra, Domenico Gulloand Hugo Poelman for facilitating this.

6. We harmonized these pillars across the two programming periods, drawing on the more detailed subcategories from each period. For details on our classification scheme, see Table A1 in Appendix A in the supplemental data online.

7. Taken together, these classifications allow one to cover almost the entirety of committed funds per period. For the 2000-06 period, only the category 'Miscellaneous', funds for agriculture (included in the Common Agricultural Policy (CAP) in later and previous periods) and non-transport infrastructure are left out. For the 2007-13 period, only funds for 'Technical assistance', non-transport infrastructure and institutional capacity are not considered. In total, we cover $91 \%$ and $97 \%$ of the total allocated funds for the 2000-06 and 2007-20 periods respectively.

8. In addition, generalized method of moments (GMM) estimates, which control in part for endogeneity issues using distributed lags of the explanatory variables as instruments, produce on the whole qualitatively similar results (available from the authors upon request).

9. The correlation coefficient for the two expenditures series in the 2000-06 period is -0.056 . All numbers quoted here come from the authors' own calculations based on the Public Expenditure Statistical Analyses (PESA) reports of the UK Office for National Statistics (ONS) (various years) and the authors' own data on EU Cohesion Policy commitments and payments.

10. All data come from EUROSTAT, with the exception of data on unemployment and gross value added, which come from the National On-line Manpower Information System (NOMIS) database of the ONS. For descriptive statistics on these and all other variables used in the analysis, see Table A2 in Appendix A in the supplemental data online; for a summary of variables used to calculate the relative performance of regions before each programming period, see Table A3 online.

11. See note 20.

12. We also use an alternative to this test by taking the interaction between each standardized measure of strength (before ranking) per category and the per capita expenditures in the same category. Unlike the variable presented in the text, which tries to capture the total effect of expenditures targeting areas of advantage, the estimated coefficient for this interaction term captures the extra growth generated by each expenditure category as a region's performance (advantage) in this category improves.

13. In the empirical analysis we complement this with an alternative measure of overall vertical need, calculated as the inverse rank of the regions with regard to their GDP per capita at the beginning of each programming period.

14. For example, for 2007-13, the West Midlands ranked last in terms of performance with regards Human resources, showing a heightened 'need' in this pillar; but it was ninth in terms of Transport infrastructure, thus showing a much less urgent need there. For this region, Human resources was ranked as a higher priority than Transport infrastructure.

15. The measures of misalignment calculated from these indicators are presented in Figure A1 in Appendix A in the supplemental data online.

16. As noted above, the analysis of 'need' departs from the GDP-based definition of performance and thus direct comparisons with the actual income levels of the regions cannot be made.

17. This positive relationship is also confirmed when EU funds are normalized by GDP (see Table A4 in Appendix $A$ in the supplemental data online).

18. Di Cataldo (2017) finds evidence of such a negative effect in the case of South Yorkshire.

19. Following a recommendation of a referee, we tested all the models for problems of spatial autocorrelation (Lagrange multiplier test statistics for error and lag dependence are reported in Tables 2 and 3; a full set of results obtained from spatial lag fixed-effects panel estimations using the -spregxt- module in Stata is reported in Tables A5 and A6 in Appendix A in the supplemental data online; a fuller set of results, including tests for cross-lag dependence capturing spatial spillovers from the EU variables, is available from the authors upon request). The tests raise little concern about estimation problems emanating from spatial autocorrelation and the estimated effects for our policy variables remain qualitatively (and in some cases even numerically) the same.

20. We ran a large number of robustness checks using alternative model specifications (e.g., no controls or controlling for the actual level of commitments instead of assignment) and definitions of effort (e.g., measured in absolute money terms) and need (e.g., using alternative socioeconomic variables, e.g., replacing the unit labour costs measure with a measure of average firm size for the measure of business need). The results, which are available from the authors upon request, are very robust to such changes.

21. However, the findings are specific to the UK case. The extent to which these results generalize to other countries and across the EU at large is an open question, which we hope to address in future research.

\section{ORCID}

Marco Di Cataldo (1) http://orcid.org/0000-0002-28081776

Vassilis Monastiriotis (1) http://orcid.org/0000-0003-37093119

\section{REFERENCES}

Acs, Z. J., Anselin, L., \& Varga, A. (2002). Patents and innovation counts as measures of regional production of new knowledge. Research Policy, 31, 1069-1085. doi:10.1016/S0048-7333 (01)00184-6 
Armstrong, H. (2011). European Union regional policy. In A. M. El-Agraa (Ed.), The European Union: Economics and policies (8th ed., pp. 421-440). London: Pearson Educational.

Armstrong, H., \& Wells, P. (2006). Structural funds and the evaluation of community economic development initiatives in the UK: A critical perspective. Regional Studies, 40(2), 259-272. doi:10.1080/00343400600600645

Bachtler, J., \& Begg, I. (2017). Cohesion policy after Brexit: The economic, social and institutional challenges. Journal of Social Policy, 46, 745-763. doi.org/10.1017/S0047279417000514

Bachtler, J., Martins, J. O., Wostner, P., \& Zuber, P. (2017). Towards Cohesion Policy 4.0: Structural transformation and inclusive growth. Brussels: Regional Studies Association (RSA) Europe.

Bachtrögler, J., Fratesi, U., \& Perucca, G. (2018). The influence of the local context on the implementation and impact of EU Cohesion Policy. Paper presented at the 57th European Regional Science Association (ERSA) Congress in Groningen, the Netherlands.

Barca, F. (2009). An agenda for the reformed Cohesion Policy (Report to the Commissioner for Regional Policy). Brussels.

Barca, F., McCann, P., \& Rodríguez-Pose, A. (2012). The case For regional development intervention: Place-based versus place-neutral approaches. Journal of Regional Science, 52, 134-152. doi:10.1111/j.1467-9787.2011.00756.x

Becker, S. O., Egger, P. H., \& von Ehrlich, M. (2010). Going NUTS: The effect of EU Structural Funds on regional performance. Journal of Public Economics, 94(9-10), 578-590. doi:10. 1016/j.jpubeco.2010.06.006

Becker, S. O., Egger, P. H., \& von Ehrlich, M. (2012). Too much of a good thing? On the growth effects of the EU's regional policy. European Economic Review, 56(4), 648-668. doi:10.1016/j. euroecorev.2012.03.001

Bouayad-Agha, S., Turpinn, N., \& Védrine, L. (2013). Fostering the development of European regions: A spatial dynamic panel data analysis of the impact of Cohesion Policy. Regional Studies, 47(9), 1573-1593. doi:10.1080/00343404.2011.628930

Camagni, R., \& Capello, R. (2015). Rationale and design of EU cohesion policies in a period of crisis. Regional Science Policy and Practice, 7, 25-47. doi:10.1111/rsp3.12047

Cerqua, A., \& Pellegrini, G. (2017). Are we spending too much to grow? The case of Structural Funds. Journal of Regional Science, 58, 535-563. doi:10.1111/jors.12365.

Crescenzi, R., Fratesi, U., \& Monastiriotis, V. (2017). The EU Cohesion Policy and the factors conditioning success and failure: Evidence from 15 regions. Regions Magazine, 305, 4-7. doi:10. 1080/13673882.2017.11868994

Crescenzi, R., \& Giua, M. (2016). The EU Cohesion Policy in context: Does a bottom-up approach work in all regions? Environment and Planning A: Economy and Space, 48(11), 2340-2357. doi:10.1177/0308518X16658291

Crescenzi, R., \& Giua, M. (2018). One or many cohesion policies of the European Union? On the diverging impacts of Cohesion Policy across member states (SERC Discussion Paper No. 0230). London: Spatial Economics Research Centre (SERC).

Crescenzi, R., \& Rodríguez-Pose, A. (2012). Infrastructure and regional growth in the European Union. Papers in Regional Science, 91, 487-513. doi:10.1111/j.1435-5957.2012.00439.x

Dall'erba, S., \& Le Gallo, J. (2008). Regional convergence and the impact of European Structural Funds over 1989-1999: A spatial econometric analysis. Papers in Regional Science, 87(2), 219-244. doi:10.1111/j.1435-5957.2008.00184.x

Del Bo, C., \& Florio, M. (2012). Infrastructure and growth in a spatial framework: Evidence from the EU regions. European Planning Studies, 20, 1393-1414. doi:10.1080/09654313.2012. 680587

Di Cataldo, M. (2017). The impact of EU Objective 1 funds on regional development: Evidence from the U.K. and the prospect of Brexit. Journal of Regional Science, 57, 814-839. doi:10.1111/ jors. 12337

European Commission. (2014). Sixth report on economic, social and territorial cohesion. Brussels: Investment for jobs and growth, European Commission.

Fagerberg, J. (1988). International competitiveness. Economic Journal, 98, 355-374. doi:10.2307/2233372

Farole, T., Rodríguez-Pose, A., \& Storper, M. (2011). Cohesion policy in the European Union: Growth, geography, institutions. JCMS: Journal of Common Market Studies, 49, 1089-1111. doi:10.1111/j.1468-5965.2010.02161.x

Griliches, Z. (1990). Patent statistics as economic indicators: A survey. Journal of Economic Literature, 28, 1661-1707.

Gripaios, P., \& Bishop, P. (2006). Objective one funding in the UK: A critical assessment. Regional Studies, 40(8), 937-951. doi:10. 1080/00343400600877839

McCann, P., \& Ortega-Argilés, R. (2015). Smart specialization, regional growth and applications to European Union Cohesion Policy. Regional Studies, 49(8), 1291-1302. doi:10.1080/ 00343404.2013.799769

Nehru, V., Swanson, E., \& Dubey, A. (1993). A new database on buman capital stock sources, methodology, and result (Working Paper No. 1124). Washington, DC: World Bank.

Piattoni, S., \& Polverari, L. (2016). Handbook of Cohesion Policy in the $E U$. Cheltenham: Edward Elgar.

Rodríguez-Pose, A., \& Fratesi, U. (2004). Between development and social policies: The impact of European Structural Funds in Objective 1 Regions. Regional Studies, 38(1), 97-113. doi:10. 1080/00343400310001632226

Sinclair, M. T. (1998). Tourism and economic development: A survey. Journal of Development Studies, 34, 1-51. doi:10.1080/ 00220389808422535

Sotiriou, A., \& Tsiapa, M. (2015). The asymmetric influence of Structural Funds on regional growth in Greece. Environment and Planning C: Government and Policy, 33, 863-881. doi:10. $1177 / 0263774 X 15603905$ 